\title{
HYPERSPECTRAL LIDAR IN NON-DESTRUCTIVE 4D MONITORING OF CLIMATE VARIABLES
}

\author{
S. Kaasalainen ${ }^{\text {a, } *, \text { T. Hakala }}{ }^{\text {a }}$, O. Nevalainen ${ }^{\text {a }}$, E. Puttonen ${ }^{\text {a }}$, K. Anttila ${ }^{\text {a,b }}$ \\ ${ }^{a}$ Finnsih Geodetic Institute, Sanna.Kaasalainen@fgi.fi \\ ${ }^{\mathrm{b}}$ Finnish Meteorological Institute, Meteorological research Kati.Anttila@fmi.fi
}

\section{Commission VII}

KEY WORDS: Laser scanning, Spectroscopy, Time series, Environmental studies

\begin{abstract}
:
The first applications of a prototype 8-channel full waveform active hyperspectral lidar (HSL) show a possibility to determine various target 3D characteristics with remote observations. The results open up a prospect for four-dimensional (4D - a three dimensional target representation with time as a fourth dimension) monitoring of important climate variables, such as those related to tree physiology or snow pollution.
\end{abstract}

\section{BACKGROUND}

Multispectral three-dimensional (3D) target characteristics can be measured using dual or multi-wavelength terrestrial light detection and ranging (lidar) instruments, which have become available through active research in the field during recent years (Gaulton et al., 2013, Douglas et al., 2012, Tan and Narayanan, 2004, Wallace et al., 2012, Wei et al., 2012, Woodhouse et al., 2011). New applications using multi or hyperspectral laser scanning have increased quite recently, and the high future potential of these instruments has been widely acknowledged. Three-dimensional (3D) distributions of vegetation biochemical properties were measured together with spectral indices using the Salford Advanced Laser Canopy Analyser (SALCA), a dualwavelength terrestrial laser scanner (Gaulton et al., 2013). The Dual-Wavelength Echidna Lidar (DWEL) (Douglas et al., 2012) is also a full-waveform ground based laser scanner, and it was shown to improve the retrieval of forest structural parameters. A tunable 4-channel canopy lidar has also been introduced for simultaneous retrieval of vegetation structure and spectral indices (Woodhouse et al., 2011).

A spaceborne dual-wavelength lidar application has also been presented by Hancock et al., (2012) to separate ground and canopy returns using the spectral ratio to complement the canopy height from laser scanning.

This paper presents preliminary results for an 8-channel hyperspectral lidar for full-waveform laser scanning (Hakala et al., 2012). The hyperspectral scanning lidar is based on supercontinuum technology (see Manninen et al., 2014 and references therein), and combines active hyperspectral imaging and full-waveform laser scanning with the same instrument in one measurement. Thus, by including spectral data in each member of the point cloud, we can get information on the surface material of the target in three dimensions (3D). Repeating the measurement over time, a 4D representation, i.e., a time series, of the object is possible. The instrument and measurements are presented in Sect. 2. The results and conclusion are in Sections 3 and 4, respectively.

\section{THE HYPERSPECTRAL LIDAR}

The HSL prototype has 8 spectral channels in $500-1600 \mathrm{~nm}$. The continuous laser spectrum allows the selection of spectral channels from this range according to the application. The time of flight is recorded for the reflected laser pulses for retrieving the range distance, and the spectrum for each point is recorded with a spectrograph and a 16-element avalanche photodiode (APD) array connected to an 8-channel high-speed digitizer (see Hakala et al., 2012 for more details). As an example of results, we present a case study for a scots pine sample.

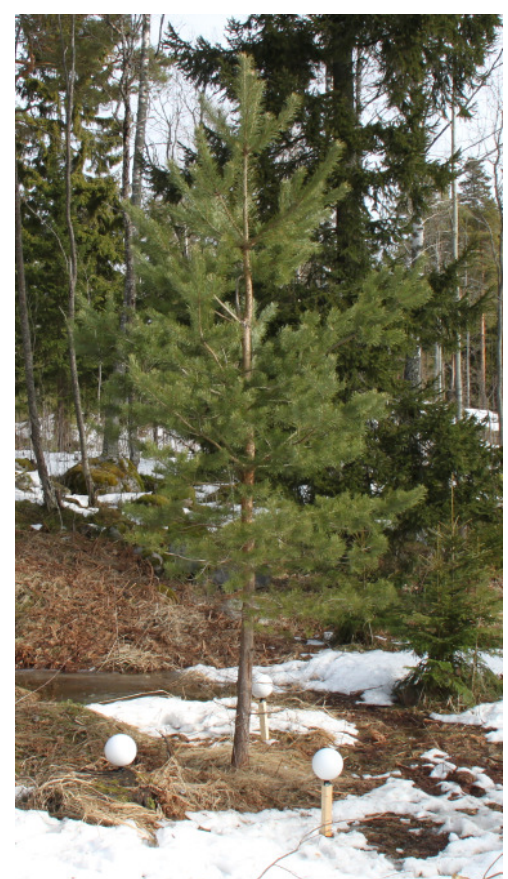

Figure 1. The pine sample before the measurement in April 2013. The white spherical reference targets visible in the image were used for the co-registration of scans.

The measurements for this study were made during the growing season 2013. A time series of a Scots pine (Pinus sylvestris L.)

\footnotetext{
* Corresponding author.
} 
sample was produced by scanning five times during the 2013 growth season (May-Nov 2013). Fig. 1 presents the sample before the beginning of the growing season in April 2013. The HSL instrument was mounted on a portable cart, and the tree was scanned from at least two directions each time. Eight wavelength bands ranging from 500 to $1300 \mathrm{~nm}$ were used in the analysis. The full-width at half-maximum (FWHM) of the channels was about $20 \mathrm{~nm}$.

The needle samples were taken immediately after each scan for laboratory analysis at the Finnish Forest Research Institute (METLA). The samples were extracted from branches at six different locations in the tree, according to needle cohorts (current year needles, and 1-, 2, and 3-year old needles). The chlorophyll was analysed spectrophotometrically following the extraction with dimethyl-sulfoxide (DMSO). The chlorophyll concentrations were then compared with the vegetation indices retrieved from the HSL spectra. Furthermore, the correlation between HSL spectral data with abundances of chlorophyll and nitrogen for pine shoots and grain samples has also been shown in our previous studies (Nevalainen et al., 2013).
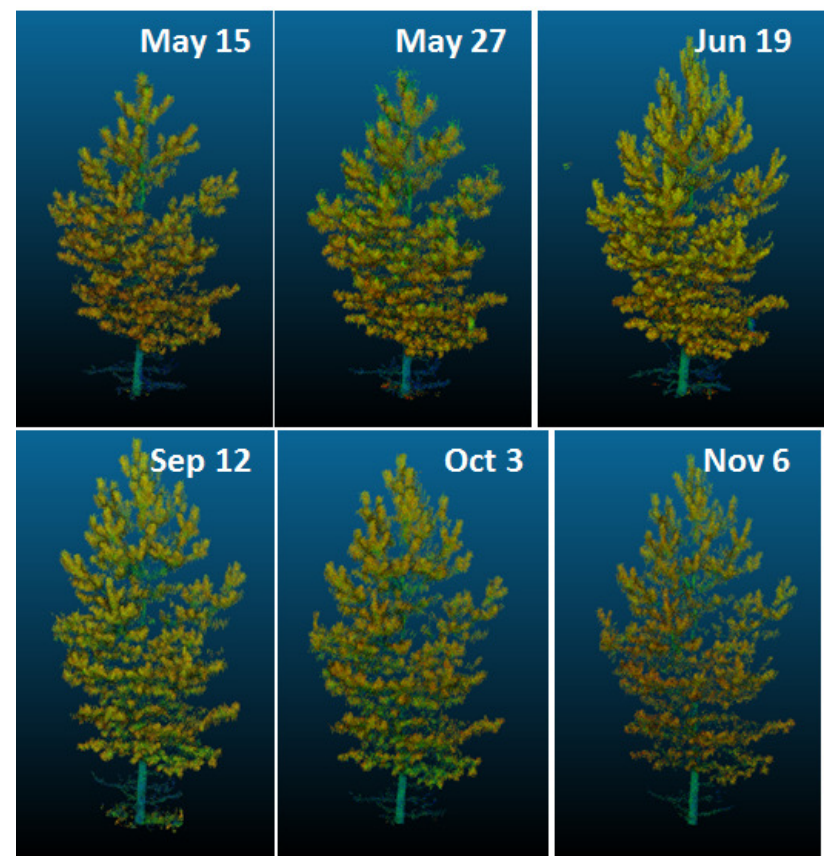

Figure 2. HSL time series (growing season 2013) of NDVI plotted over the HSL point cloud shows the new growth in spring as well as dying and falloff of the old parts.

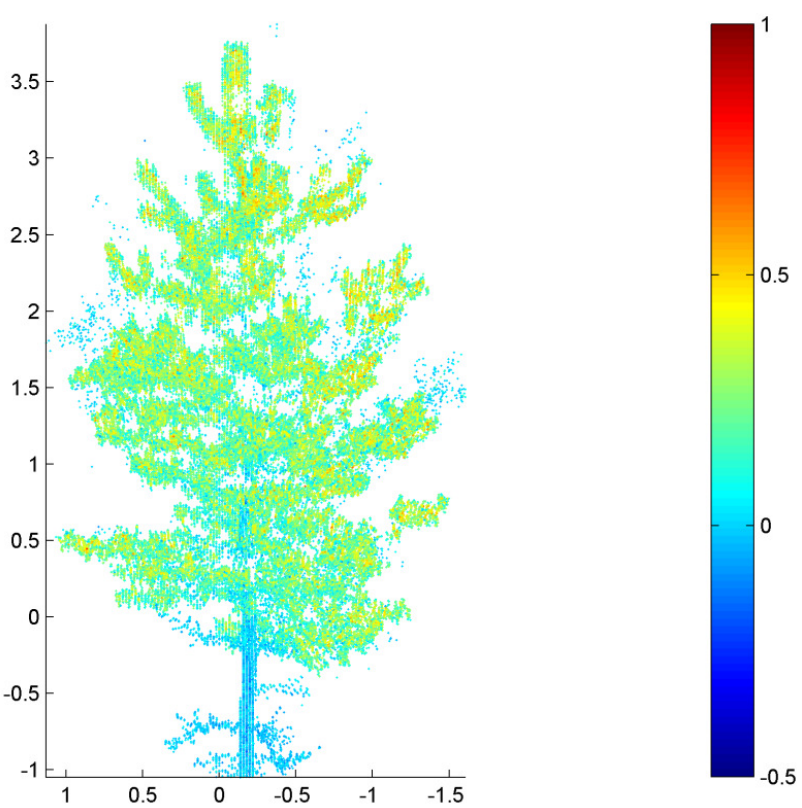

Figure 4. A 3D distribution of the Modified Triangular Vegeation Index 2 (MTVI2) over the pine sample. This index is correlated to the leaf area index (LAI).

\section{RESULTS}

An example of branch/needle level tree monitoring is shown in Fig. 2, where the Normalized Difference Vegetation Index (NDVI) (Rouse et al., 1974) has been plotted over a Scots pine sample. Other indices, such as those describing the chlorophyll A content were carried out, and validated with laboratory analysis. Examples of the chlorophyll-sensitive Modified Chlorophyll Absorption Ratio Index (MCARI) (Wu et al., 2008) and the Modified Triangular Vegetation Index 2 (MTVI2) (Haboudane, 2004), predicting the leaf-area-index (LAI), are shown in Figs. 3-4. Similar results have been obtained for nitrogen in grain samples (cf. Nevalainen et al., 2013), and our ongoing study aims at generalizing these first results into tree level.

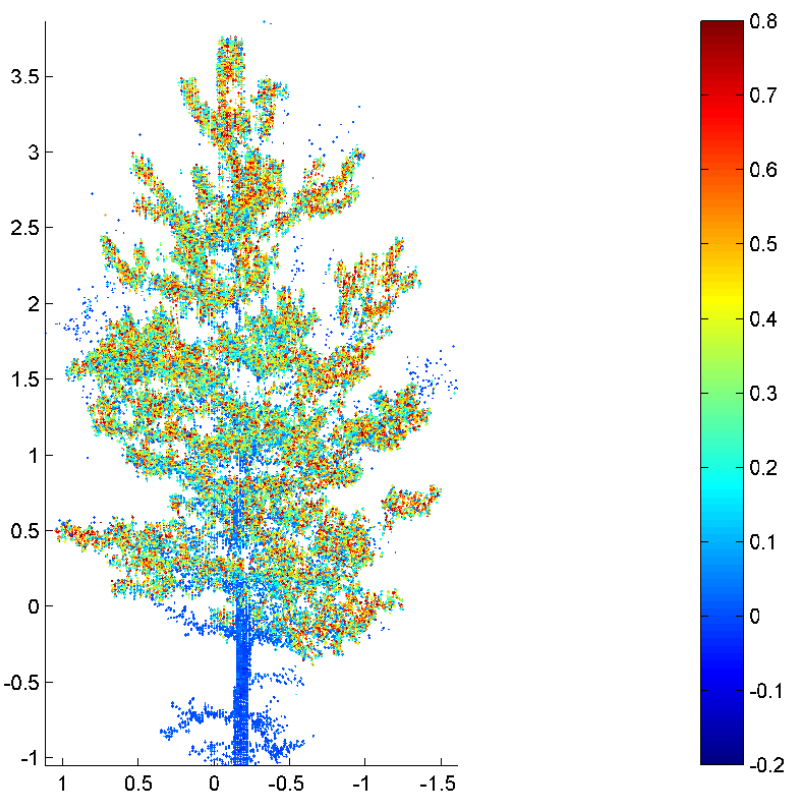

Figure 3. A 3D distribution of Modified Chlorophyll Absorption Ratio Index (MCARI) over the pine sample. 
The initial results suggest that laboratory sampling may not fully represent the entire target (in tree level), because of the spatial variation of the physiological conditions between the tree parts. The variation is better observed when the sampling has been carried out over the entire point cloud, rather than just a few needle samples extracted for laboratory. Thus the HSL approach has potential of replacing the current destructive sampling in tree ecophysiology. Extensive study is needed to improve the accuracy of the method for full-scale measurements of plant ecophysiology and other important environmental characteristics, such as pollution levels related to snow albedo.

\section{CONCLUSION}

The HSL provides a unique opportunity for measuring the accurate full profiles of vegetation indices in needle/leaf level, and repeat the measurement over time. The approach has potential for replacing destructive and labour-intensive manual sampling with remote observations. Although our first results are promising, they also show that extensive experiments are needed to establish and validate this approach.

Our ongoing studies focus on finding the connection between laboratory analysis and tree-level HSL spectral point clouds. Similar studies are going on for quantifying the amounts of chemical compounds in snow surfaces. Combining these two aspects has also potential for analysing the snow in boreal forests. All these experiments must be complemented with physical models of vegetation scattering, in order to fully understand the laser interaction with the plants being studied.

One of our near-future aims is also to improve the instrument in terms of spatial and spectral resolution, measurement range, and better portability for field applications. This will also enable to increase the point density for a better coverage of the sample, thus improving the accuracy of the results.

\section{REFERENCES}

Douglas, E. S., Strahler, A., Martel, J., Cook, T., Mendillo, C., Marshall, R., Chakrabarti, S., Schaaf, C., Woodcock, C., Li, Z., Yang, X., Culvenor, D., Jupp, D., Newnham, G. Lovell, J., 2012. DWEL: A Dual-Wavelength Echidna Lidar for groundbased forest scanning, pp. 4998-5001, IEEE.

Gaulton, R., Danson, F. M., Ramirez, F. A. and Gunawan, O., 2013. The potential of dual-wavelength laser scanning for estimating vegetation moisture content, Remote Sensing of Environment, 132, 32-39.

Haboudane, D., 2004. Hyperspectral vegetation indices and novel algorithms for predicting green LAI of crop canopies: Modeling and validation in the context of precision agriculture. Remote Sens. Environ. 90, 337-352. doi:10.1016/j.rse.2003.12.013

Hakala, T., Suomalainen, J., Kaasalainen, S. Chen, Y., 2012. Full waveform hyperspectral LiDAR for terrestrial laser scanning, Optics Express, 20(7), 7119-7127.

Manninen, A., Kääriäinen, T., Parviainen, T., Buchter, S., Heiliö, M., and Laurila, T., 2014. Long distance active hyperspectral sensing using high-power near-infrared supercontinuum light source. Optics Express, 22, 7172.
Nevalainen, O., Hakala, T., Suomalainen, J., and Kaasalainen, S., 2013. Nitrogen concentration estimation with hyperspectral LiDAR, ISPRS Ann. Photogramm. Remote Sens. Spatial Inf. Sci., II-5/W2, 205-210.

Rouse, J. W., R. H. Hass, J. A. Schell, D. W. Deering, and J. C. Harlan. 1974. Monitoring the vernal advancement of retrogradation of natural vegetation. In NASA/GSFC. Greenbelt, MD.

Tan, S., Narayanan, R.M., 2004. Design and performance of a multiwavelength airborne polarimetric lidar for vegetation remote sensing. Appl. Opt. 43, 2360-8.

Wallace, A., Nichol, C., Woodhouse, I., 2012. Recovery of Forest Canopy Parameters by Inversion of Multispectral LiDAR Data. Remote Sens. 4, 509-531. doi:10.3390/rs4020509

Wei, G., Shalei, S., Bo, Z., Shuo, S., Faquan, L., Xuewu, C., 2012. Multi-wavelength canopy LiDAR for remote sensing of vegetation: Design and system performance. ISPRS J. Photogramm. Remote Sens. 69, 1-9. doi:10.1016/j.isprsjprs.2012.02.001

Woodhouse, I. H., Nichol, C., Sinclair, P., Jack, J., Morsdorf, F., Malthus, T. J. Patenaude, G., 2011. A Multispectral Canopy LiDAR Demonstrator Project, IEEE GRSL, 8(5), 839-843.

Wu, C., Niu, Z., Tang, Q., Huang, W., 2008. Estimating chlorophyll content from hyperspectral vegetation indices: Modeling and validation 148, 1230-1241. doi:10.1016/j.agrformet.2008.03.005

\section{ACKNOWLEDGEMENTS}

This research was funded by the Academy of Finland research project "Mobile hyperspectral laser remote sensing". The authors want to thank Raisa Mäkipää at the Finnish Forest Research Institute (METLA) for help in the reference measurements. 